\title{
Comunicação Gerativa: um diálogo com Oliver Sacks ${ }^{1}$ \\ Generative Communication: a dialogue with Oliver Sacks
}

\author{
JOSÉ LUIZ BRAGA a \\ Universidade do Vale do Rio dos Sinos, Programa de Pós-Graduação em Ciências da Comunicação. \\ São Leopoldo - RS, Brasil
}

\section{RESUMO}

O texto elabora um diálogo com o estudo de Oliver Sacks sobre a surdez. A situação-limite criada pela surdez oferece acuidade sobre características do fenômeno comunicacional. Algumas premissas desenvolvidas em textos anteriores são apresentadas, como ângulos para o diálogo. No livro de Sacks, que aborda o problema da surdez por uma diversidade de perspectivas, o artigo seleciona observações e proposições que ora corroboram aquelas premissas, ora são tomadas como desafios à reflexão. Do diálogo entre as proposições básicas inicialmente apresentadas e as pistas obtidas no estudo de Sacks, resultam inferências relacionadas à situação-limite e derivações pertinentes ao fenômeno em perspectiva mais abrangente.

Palavras-chave: Comunicação gerativa, surdez, língua de sinais

\begin{abstract}
The study develops a dialogue with Oliver Sacks'study on deafness. The limit situation created by deafness offers acuity on characteristics of the communicational phenomenon. Some assumptions developed in previous texts are presented as angles for dialogue. In Sacks' book, which addresses the problem of deafness through a variety of viewpoints, the article selects observations and proposals that corroborate those assumptions or present themselves as challenges to reflection. From the dialogue between the basic propositions initially presented and the clues obtained in Sacks' study, the text draws inferences relating to the limit situation and derivations pertaining to the phenomenon in a broader perspective.
\end{abstract}

Keywords: Generative communication, deafness, sign language

\author{
${ }^{1}$ Uma versão preliminar deste \\ artigo foi apresentada no GT de \\ Epistemologia da Comunicação \\ (Compós), São Paulo, 2017. \\ Agradeço aos/às colegas pelo \\ debate que estimulou revisões \\ significativas no texto. \\ a Doutor, professor titular do \\ Programa de Pós-Graduação \\ em Ciências da Comunicação \\ da Unisinos. Orcid: http://orcid. \\ org/0000-0003-3742-1119. \\ E-mail: jlbraga@via-rs.net
}




\section{INTRODUÇÃO: O EIXO DA CONVERSA}

$V$ ENDO VOZES: UMA viagem ao mundo dos surdos, de Oliver Sacks, oferece um estudo complexo e diversificado sobre uma situação-limite no que se refere à comunicação humana: a questão da surdez, inscrita nos processos culturais pertinentes aos indivíduos portadores. A perspectiva neurológica de Sacks se articula a reflexões de ordem antropológica e linguística, estimulando inferências pertinentes para a comunicação - relacionadas à interação entre os surdos e destes com os ouvintes.

A possibilidade de observar uma língua se instalando, sendo aprendida e exercida, mas também sendo criada como código interacional principal em tempos históricos, é o que faz a importância desta obra para a reflexão comunicacional. Os processos geradores das línguas de sinais, a partir de um estado lacunar da pessoa surda, oferecem pistas e desafios.

Como os neurologistas - que apreendem processos normais regulares sobre o cérebro e o sistema neurológico pela observação de situações não ordinárias - podemos estudar características do fenômeno comunicacional a partir de circunstâncias menos frequentes. As situações-limite expõem relações que não percebemos com clareza nos âmbitos da normalidade - nos quais são naturalizadas. As relações ocorrentes não só se dão a ver por sua singularidade como iluminam, pelo contraste, as relações mais habituais, desvelando as lógicas que as sustentam.

Chego ao texto por questões referentes ao fenômeno comunicacional. Ao mesmo tempo em que busco apreender as lógicas internas do livro, rastreio aí o que complementa minhas proposições, o que as corrobora, mas também o que as tensiona. É nesse sentido que posso reivindicar essa elaboração como um diálogo.

\section{CARACTERÍSTICAS DA COMUNICAÇÃO: AS QUESTÕES QUE TRAGO PARA O DIÁlOGO}

Tenho argumentado sobre o interesse, para o conhecimento comunicacional, de desentranhar características da comunicação humana dentre os processos de diversas ordens em que o fenômeno se encontra imbricado. Nesse enfoque, não interessa buscar grandes teorias definidoras do que seja comunicação, e sim levantar características e aspectos do fenômeno em seu funcionamento. É de sua diversidade que se desenvolverão perspectivas crescentemente abrangentes, assim como a percepção de seu âmbito de validade.

Contemporaneamente, o impulso comunicacional, cada vez mais explicitado por meio da história, acabou por desenvolver profissões voltadas para atividades 
reconhecidas como de comunicação, especializando tarefas antes infusas na variedade das ações humanas. Correlatamente, vemos o desenvolvimento de tecnologias acionáveis como veículo e forma para uma comunicação ampliada. Mas, ainda que a midiatização esteja se tornando o "processo interacional de referência” (Braga, 2007), o fenômeno comunicacional tem uma presença muito mais abrangente e disseminada em todos os processos sociais. Por isso mesmo, as ciências humanas e sociais passaram, como sabemos, a incluir a comunicação entre suas questões de interesse, durante todo o século XX, o que levou a uma diversificada produção de teorias.

Entretanto, em todas aquelas ciências, as características do fenômeno permanecem imbricadas nas questões próprias de cada uma. O olhar sobre o fenômeno se restringe aí a duas perspectivas principais: a comunicação vista como epifenômeno das variáveis que interessam diretamente à ciência de enfoque; ou como uma variável interveniente a ser cuidada (eventualmente em função das consequências práticas de sua incidência). Isso não torna menos relevante a oferta desses conhecimentos, mas solicita um trabalho adicional, para podermos ir além das perguntas e hipóteses que interessam estritamente à ciência em pauta.

Por isso mesmo, é preciso decidir o que descrever, para distinguir o que pode ser atribuído à comunicação e o que pertence aos processos sociais os mais diversos dos quais o fenômeno participa. Assumindo que a comunicação comparece em praticamente todos os processos humanos, entende-se que a meta de desentranhamento não é simples.

Tenho adotado, nesse aspecto, duas aproximações. Uma delas corresponde aos estudos de interface - nos quais, investigando qualquer processo social e acionando os conhecimentos e teorias habitualmente chamados para sua análise e interpretação, devemos estar atentos à pergunta: o que há aí de propriamente comunicacional?

Outra tática complementar é a de abordagens transversais a diversos campos especializados. Trata-se de perceber processos comunicacionais que se manifestam em uma diversidade de ambientes de conhecimento, modalizados por estes. Trata-se de buscar características que se mantêm, malgrado as modalizações diversas.

Neste artigo, entretanto, procuro explorar uma terceira alternativa - o exame de situações-limite que apresentam problemas especiais para o exercício da comunicação. Essas situações tensionam de tal modo os processos comunicacionais envolvidos que algumas características podem se dar a ver com mais acuidade que nas situações de normalidade - aquelas com as quais estamos de tal modo habituados que nos parecem simplesmente naturais. 
Para dialogar com as perspectivas oferecidas por Sacks, trago características do fenômeno garimpadas em estudos anteriores. Seu alinhamento com aquelas expostas por Sacks permite corroborações e tensionamentos, viabilizando percepções adicionais.

Assumo que a comunicação envolve sempre um aspecto tentativo (Braga, 2010a). Os objetivos comunicacionais dos participantes levam a estratégias eventualmente muito decididas e direcionadoras. Mas há sempre uma margem de ensaio-e-erro. A comunicação é um trabalho humano, com tendências individuais e grupais diversas que se articulam em processo.

Por meio daquele ensaio e erro reiterado, o processo da comunicação se exerce pelas linguagens já disponíveis no contexto cultural, mas também gera linguagens, quando não as encontra prontas. Estratégias e regras são elaboradas com base na percepção do que dá ou não dá certo na prática das interações. Essas regras são transferidas para outras e outras situações. Isso significa que a comunicação não é apenas tentativa (como se fosse aleatória ou jamais superasse o ensaio e erro). Ela é também um resultado buscado. Os processos exitosos tendem a ser replicados, reforçando o jogo de probabilidades em favor do que se pretende e viabilizando tentativas mais escoladas. Embora sempre em algum grau abaixo da certeza, isso desenvolve uma dinâmica: à medida que a corroboração da eficácia e os sistemas de regras interacionais ganham firmeza e se expandem, e os desajustes desmoronam - ou ganham complexidade crescente pelos reajustes necessariamente feitos.

Dado que a realidade social é histórica, nossos sistemas de regras (códigos interacionais) se modificam e se substituem no tempo. Mesmo porque o código, sempre necessário, é insuficiente. O ajuste entre as regras e o exercício prático delas se faz por inferências, requeridas pelo jogo entre os objetivos dos participantes e as ocorrências inusitadas do entorno. Esse processo mantém a instabilidade criativa das próprias regras (Braga, 2011).

Para interagir, os seres humanos precisam então de alguma coisa compartilhada e de lacunas na possibilidade de ação em comum. Os participantes buscam articular, em função de um objetivo em comum ou pela presença de objetivos em tensionamento mútuo, as diferenças que de algum modo fazem problema, o que não implica que a comunicação necessariamente busque consensos ou que seja sempre negociadora.

Esse trabalho de reajuste, de invenção, de aperfeiçoamento das regras, não pode ser uma tarefa do próprio código, mas sim de seu uso, que exige, para além do exercício das regras codificadas, competências de sua adaptação às circunstâncias. 
Como a comunicação é requerida para desenvolver culturalmente essas regras, não pode ser um epifenômeno destas. A possibilidade - e a necessidade - de interação social deve ter como base última processos humanos compartilhados de ordem biológica e não cultural. Assumimos que o ponto inicial sobre o qual se constitui o processo comunicacional é a articulação de duas características da espécie. Na ausência de um instinto articulador entre os indivíduos da espécie (como o possuem as abelhas, por exemplo), temos, no entanto, uma competência instintiva para a imitação e para a inferência. Como a reprodução imitativa é apenas aproximada, a inferência compõe diretamente o processo (Braga, 2015).

Daí aquele aspecto tentativo constante, que faz parte essencial do senso comum, mas também de todos os processos interacionais, ainda que crescentemente especializados.

\section{COMUNICAÇÃO E LINGUAGEM: O QUE OUÇO EM VENDO VOZES}

Sacks estuda a situação da surdez - de nascimento ou por doença nos anos iniciais de vida - em diversos ângulos de conhecimento, para além de sua perspectiva neurológica. Em nenhum momento o conceito de comunicação é sistematicamente elaborado, mas atravessa todas as reflexões do livro. Essa presença reiterada viabiliza organizar as referências ao autor em tópicos que, embora não correspondam à estrutura do livro, favorecem sua interpretação em perspectiva comunicacional: códigos; pensamento e cultura; aquisição da língua; geração da língua.

Para tornar explícita a distinção entre a exposição do pensamento de Sacks (em que busco ser fiel às perspectivas do livro) e minhas interpretações pessoais, destacadas em itálico.

\section{Códigos}

Estamos de tal modo habituados à língua oral como o modo básico de nos comunicarmos uns com os outros, que a impossibilidade de aquisição e uso desse código aparece, imediatamente, como um corte dramático da realidade. A surdez, como impedimento neurológico, manifesta-se à percepção essencialmente como patologia.

Oliver Sacks, no entanto, oferece informações e reflexões de ordem histórica e linguística evidenciando o sentido pleno da língua de sinais (LS). No final da década de 1950, era considerada apenas como uma espécie de pantomima. Mas William Stokoe mostrou, em 1960, que a língua de sinais "satisfazia todos os critérios linguísticos de uma língua genuína, no léxico e na sintaxe, na 


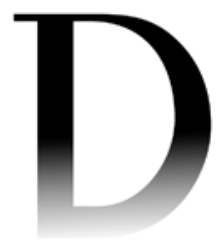

${ }^{2}$ No original em inglês: "satisfied every linguistic criterion of a genuine language, in its lexicon and syntax, its capacity to generate an infinite number of propositions". Essa e demais traduções são da versão em português do livro (Sacks, 2010).

${ }^{3}$ No original: "propositionize". Caso o leitor queira cotejar as citações traduzidas com o original, nas notas de rodapé está citado cada trecho utilizado no texto seguindo a edição original de 2000.

${ }^{4}$ No original: "preserves [...] both of its faces - the iconic and the abstract, equally, in complementarity".

${ }^{5}$ No original: "grammaticization of space".

\footnotetext{
${ }^{6}$ Entretanto, a aprendizagem da leitura e da escrita a partir do domínio de uma língua de sinais é complexa, pois não há correspondência correlata à que ocorre entre língua oral e língua escrita. Para o usuário de sinais, a escrita é uma segunda língua, tão distante como uma língua estrangeira (Hamm, 2008: 38).
}

capacidade de gerar um número infinito de proposições”2 (Sacks, 2010: 70). Um aspecto fundamental da caracterização da LS como uma verdadeira língua é sua capacidade de "proposicionar"3 (Ibid.: 28).

Os gestos não buscam apenas representar imitativamente a realidade referida. A língua de sinais "preserva [...] suas duas faces - a icônica e a abstrata, igualmente, de um modo complementar"4 (Ibid.: 104). O gesto mantém relações icônicas de referência; mas envolve também regras e relações entre os componentes. Elabora-se aí uma "gramaticação do espaço"5 (Ibid.: 163). Como em toda gramática, encontramos um sistema de regras, com restrições e liberdades possíveis.

Assinalamos que uma característica recorrente de todos os sistemas interacionais é a de apresentar entre estas liberdades possíveis a de contrariar criativamente as próprias regras em benefício da expressão e da geração de sentidos; ou, adaptativamente, para abordar situações não previstas no sistema.

Como código gestual e, portanto, espacial, a LS constrói estruturas tridimensionais dinâmicas (Ibid.: 71). Os componentes elementares da língua se organizam por tipos de movimentos (das mãos e do corpo), pelas configurações compostas e por localizações em que os movimentos se exercem.

Oliver Sacks observa também a competência gramatical plena da LS pela possibilidade de manipulação das regras (Ibid.: 94). Como qualquer outra língua, ela se desenvolve léxica e sintaticamente a partir dos objetivos interacionais e da necessidade das coisas a serem ditas.

Os objetivos interacionais dos participantes puxam o código em direção ao compartilhamento e às ações comunicacionais pretendidas. Por isso mesmo, a adoção de elementos significativos é circunstancial. Ainda que elementos icônicos possam ser mais ou menos evidentes (por exemplo, dedos indicador e médio apontados em um gesto para a frente, com a mão próxima do rosto, significando olhar), a complexidade proposicional é dependente das circunstâncias de surgimento e das táticas buscadas para se dizer o que há a ser dito.

O histórico feito por Sacks (2000: 24-33) a respeito da constituição formal das línguas de sinais mostra sua centralidade no desenvolvimento educacional de surdos entre 1770 e 1870 como processo de sua formação e integração; e o recuo dessa política formadora entre 1870 e 1970, em favor do ensino da oralidade (leitura labial e superação da mudez). Apenas nos anos 1960 há uma retomada de valoração das línguas de sinais, na Europa como nos Estados Unidos.

Essa história conta um embate político entre dois códigos. A língua de sinais viabiliza todos os usos interacionais, de elaboração do pensamento, de desenvolvimento cultural das comunidades de surdos - assim como o acesso à cultura universal, pela leitura ${ }^{6}$. A oralidade surda favorece uma integração direta 
na comunidade ouvinte - mas à custa do esforço enorme de verdadeiro adestramento de uma voz que não é monitorada pelo próprio falante e de uma atenção penosa dirigida ao movimento labial dos falantes para lhes adivinhar a voz.

Oliver Sacks faz uma comparação entre a oralidade imposta e a tendência natural de jovens surdos para acionar a língua de sinais (Ibid.: 37-38). No primeiro caso, há uma inserção no mundo dos falantes/ouvintes (Ibid.: 35). No segundo caso, uma produção verdadeiramente cultural que se acompanha da possibilidade de apreensão da escrita.

O que temos, portanto, na alternância referida, são dois problemas diferentes: a comunicação dentro da comunidade de surdos; e determinada comunicação entre estes e a maioria ouvinte. Sem entrar na substância dessa questão da política de códigos preferenciais, é relevante, em nossa perspectiva, observar que a pertinência dos códigos depende dos ambientes de uso e sobretudo - considerando os objetivos dos participantes - o que se pode fazer com eles, em termos interacionais. A questão do desenvolvimento cultural do pensamento se torna, então, um critério fundamental.

\section{Pensamento e cultura}

Por meio de reflexões sobre a língua de sinais e diferentes experiências da surdez, Sacks estuda relações entre língua e pensamento, por um lado; e língua e cultura, por outro (Ibid.: 16 et seq.).

Uma primeira situação (feliz) é a da criança surda filha de pais surdos - porque aí a integração entre língua, pensamento e cultura se faz espontaneamente. A criança se relaciona com intercessores que dominam o código, os modos de pensamento e o quadro cultural correlato a suas necessidades e aos objetivos sociais e culturais que decidam assumir.

Sacks observa que "a surdez em si não é o infortúnio; o infortúnio sobrevém com o colapso da comunicação e da linguagem" (Ibid.: 101). O grande risco da surdez pré-linguística é o da criança ficar sem língua (Ibid.: 20). Na circunstância da criança surda ter pais ouvintes e em determinados ambientes socioeconômicos, ela encontrará um espaço extraordinariamente tolhido para o desenvolvimento da língua e da comunicação, restringindo a flexibilidade e o alcance do pensamento (Ibid.: 19). Esse risco é ampliado pelo fato de que menos de 10\% das crianças surdas têm pais surdos (Hamm, 2008: 38).

No mundo ouvinte, sequer reparamos nessa conjunção delicada entre o pensamento e a língua, de tal forma que as duas coisas parecem imbricadas. A constatação de sua separação possível, na surdez, evidencia ao mesmo tempo a relevância humana de sua composição. Sacks observa que "se o pensamento
${ }^{7}$ No original: "deafness as such is not the affliction; affliction enters with the breakdown of communication and language". 


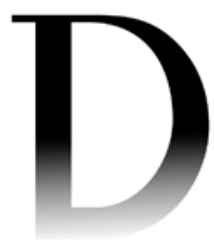

${ }^{8}$ No original: "if thought transcends language, and all representational forms, nonetheless it creates these, and needs these, for its advancement".

${ }^{9}$ No original: "A human being is not mindless or mentally deficient without language, but he is severely restricted in the range of his thoughts"

${ }^{10}$ No original: "dialogue launches language, the mind, but once it is launched we develop a new power, 'inner speech', and it is this that is indispensable for our further development, our thinking".

${ }^{11}$ Ou seja: não estão inscritas no código genético da espécie como um instinto.

${ }^{12}$ No original: "neither language nor the higher forms of cerebral development occur 'spontaneously'; they depend on exposure to language, communication, and proper language use".

${ }^{13}$ No original: "To be defective in language, for a human being, is one of the most desperate of calamities, for it is only through language that we enter fully into our human estate and culture, communicate freely with our fellows".

transcende a língua e todas as formas representativas, ainda assim ele as cria, e precisa delas, para seu desenvolvimento"8 (Ibid.: 150).

"Um ser humano não é desprovido de mente ou mentalmente deficiente sem uma língua, porém está gravemente restrito no alcance de seus pensamentos"9 (Sacks, 2010: 44). Assim, “o diálogo impulsiona a linguagem, a mente; mas depois que esta é impulsionada, desenvolvemos um novo poder, a 'fala interna', e esta é que é imprescindível para nosso desenvolvimento mais amplo, nosso pensamento"10 (Ibid.: 67).

Considero que a "fala interna" não é apenas código internalizado, mas o próprio processo comunicacional - a voz de nossos interlocutores. Nosso diálogo interno corresponde à ponderação entre diferentes perspectivas sobre o que se percebe no mundo e como se pode agir sobre este. É porque podemos realizar internamente esse diálogo, negociar com as vozes dos outros, que efetivamente criamos cultura - o indivíduo se inscreve nos processos coletivos - o que faz articular a especificidade de cada um, sua diferença, sua singularidade, no conjunto diversificado. Constituímos, no mesmo gesto, nossa cultura como grupo e nossa identidade como indivíduo. A esse processo de articulação é que podemos chamar de comunicação.

A observação da surdez, quando esta leva à disjunção entre o pensamento e a linguagem, é que permite compreender - pela situação-limite da separação - o que a comunicação realiza como processo integrador.

Uma questão manifesta para o estudioso que se volta para esse tipo de situação-limite, na surdez, é a constatação de que "nem a língua nem as formas superiores de desenvolvimento cerebral ocorrem 'espontaneamente ${ }^{\text {'11 }}$; dependem da exposição à língua, da comunicação e uso apropriado da língua"12 (Ibid.: 96). "Ser deficiente na linguagem, para um ser humano, é uma das calamidades mais terríveis, porque é apenas por meio da língua que entramos plenamente em nosso estado e cultura humanos, que nos comunicamos livremente com nossos semelhantes ${ }^{13}$ (Ibid.: 19).

Essas são, então, as duas faces da língua. De um lado, se articula com os processos do pensamento, viabilizando e estimulando as formas superiores de desenvolvimento cerebral; do outro lado, remete à cultura.

Os dois processos estimulados pela presença da língua se mostram como aspectos de uma mesma dinâmica. A aquisição da língua transforma o pensamento em cultura. A diferença de alcance entre o pensamento idiossincrático do indivíduo isolado (mesmo se criativo, aberto à percepção do mundo, inquisitivo) e o pensamento estimulado pelo uso da língua é o resultado de uma comunicação que completa a espécie e o espécime para além do genético. Ou seja, a língua não é importante apenas para pensar (em padrões operativos superiores do cérebro) -é importante para pensar com. A língua, como um dispositivo interacional, não 
viabiliza apenas a expressão de meu pensamento e a escuta (no caso da surdez, evidentemente, a visão) do pensamento do outro. Viabiliza também - e, mais que isso, torna inevitável - a voz do outro em mim, quer esta voz seja auditiva ou visual.

É nesse aspecto que podemos sobretudo considerar a comunicação como instituinte da condição humana. Como os instintos (de que certamente dispomos, para uma grande amplitude e diversidade de tarefas) não nos fornecem uma repetibilidade comportamental genética de indivíduo a indivíduo ${ }^{14}$, as tensões da diferença e o esforço do ajuste são atribuídos aos processos comunicacionais, que produzem nossa cultura e a inserção do pensamento nos fluxos da cultura.

A voz do outro é inicialmente pré-linguística - mas cria a ponte para a emergência da língua, oral ou gestual, viabilizando sua aquisição. Podemos dizer também que o pensamento-percepção da criança se externaliza e se desenvolve pela interação com o outro.

\section{Aquisição da língua}

A aquisição normal da língua oral é aquela que se faz em situação - a criança tem aí suas experiências inaugurais do mundo articuladas com a experiência da língua, o que permite organizar esse mundo em sintonia com o outro (normalmente, os pais), que já tem o manejo da língua. Não há propriamente ensino e aprendizagem da língua nessa aquisição - ela emerge da interação.

Sacks refere a perspectiva de Vygotsky sobre a aquisição da língua pela criança: "[nossos sentidos] são naturais. É possível desenvolvermos sozinhos, naturalmente, as habilidades motoras. Mas não podemos adquirir sozinhos uma língua"15 (Ibid.: 59). Ainda que seja necessária alguma capacidade inata (genética) para o exercício de linguagens, "essa capacidade só é ativada por uma outra pessoa que já possui capacidade e competência linguísticas"16 (Ibid.: 59).

Isso corresponde a dizer que

a criança possui uma experiência do mundo independente que lhe é dada pelos sentidos, e é essa experiência que forma uma correlação ou confirmação da língua da mãe e, por sua vez, recebe dela seu significado. É a língua da mãe, internalizada pela criança, que permite a esta passar da sensação para o "sentido", ascender do mundo perceptivo para o conceitual ${ }^{17}[$ [... Mas as palavras da mãe, e o mundo por trás delas, não teriam sentido para o bebê se não correspondessem a algo encontrado em sua própria vivência ${ }^{18}$. (Sacks, 2010: 59)

O que podemos chamar, então, de aquisição normal da linguagem é essa correlação situacional entre a experiência direta de percepção do mundo pela criança
${ }^{14}$ Que encontramos, em forte grau, em uma variedade de animais, como os insetos sociais (abelhas, formigas, térmites).
${ }^{15}$ No original: "are 'natural'. One can develop motor skills, naturally, by oneself. But one cannot acquire language by oneself".

${ }^{16}$ No original: "this hability is only activated by another person who already possesses linguistic power and competence".

${ }^{17}$ No original: "has an independent experience of the world given to him by his senses, and it is this which forms a correlation or confirmation of the mother's language, and in turn, is given meaning by it. It is the mother's language, internalized by the child, that allows it to move from sensation into 'sense', to ascend from a perceptual into a conceptual world".

${ }^{18}$ No original: "But the mother's words, and the world behind them, would have no sense for the infant unless they corresponded to something in his own experience". 


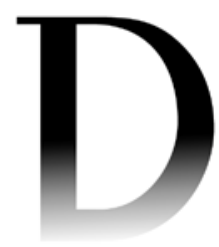

${ }^{19}$ No original: “The languageless deaf may indeed be as if imbecilic - and in a particularly cruel way, in that intelligence, though present and perhaps abundant, is locked up so long as the lack of language lasts".

${ }^{20}$ No original: "the especial peril that threatens human development, both intellectual and emotional, if the healthy acquisition of language fails to occur".

e um mundo mais amplo trazido pelas palavras de alguém que já as domina e usa em situação, produzindo sentido.

Essa situação de aquisição não se dá como aprendizagem de um código a ser acionado em determinadas circunstâncias; mas sim se realiza como experiência vivida de construção de sentido por meio do qual o código se instala e vai, correlatamente, fazendo-se operacional, porque se evidencia como pertinente àqueles sentidos.

O que Oliver Sacks mostra, então, é que a aquisição da língua de sinais entre crianças e pais surdos é idêntica a nossa aprendizagem do código linguístico da oralidade. É preciso, certamente, que os pais surdos tenham a linguagem e seu uso comunicacional, para que as coisas se passem nesse processo de normalidade.

É por isso que a surdez pré-linguística se põe como ocasião de risco. Sacks observa que a surdez pode ser devastadora: "Os surdos sem língua podem de fato ser como imbecis - e de um modo particularmente cruel, pois a inteligência, embora presente $[\ldots]$, fica trancada pelo tempo que durar a ausência de uma língua"19 (Ibid.: 28, grifo no original).

As crianças surdas nascidas em ambiente ouvinte, além de não terem facilmente detectada a surdez, são eventualmente assumidas como mentalmente deficientes - embora seu raciocínio tolhido não seja decorrente da falta de inteligência, mas tão somente da barreira de acesso à cultura devido à ausência de língua - e à falta de condições interacionais para adquirir ou inventar essa língua.

Sacks estuda casos de jovens e adultos, privados daquela primeira aquisição de língua em situação. São referências a estudos nos séculos XIX e XX e a observações empíricas do próprio Sacks. Ele observa, nessas histórias, “o perigo especial que ameaça o desenvolvimento humano, tanto intelectual como emocional, se deixar de ocorrer a aquisição apropriada de uma língua”20 (Ibid.: 58).

Com os surdos em tal situação, pode ocorrer uma aquisição posterior da língua de sinais, distinta do encontro concomitante entre o mundo, a língua e o outro. O indivíduo já dispõe de uma experiência - idiossincrática e pobremente interacional do mundo, lacunar por falta de processos comunicacionais intercessores suficientes - quando encontra um ambiente de aquisição da língua de sinais.

A situação-limite que se refere à comunicação não é então a surdez em si - por mais que essa condição traga efetivamente dificuldades para seu portador. O que consideramos como situação-limite é a separação entre as experiências iniciais do mundo e uma ativação de competências interacionais, que deveriam estar correlacionadas como modo de ingresso na cultura pela formação de uma linguagem.

Dada a identidade sistêmica entre línguas de sinais e línguas orais, podemos inferir que uma criança com audição, afastada de possibilidades interacionais, 
estaria na mesma situação disjuntiva. Efetivamente, Sacks refere essaocorrência à história de Kaspar Hauser (Ibid.: 50).

Oliver Sacks conheceu e acompanhou, durante o estudo que levou à elaboração do livro, um jovem de onze anos, Joseph, cuja surdez só fora descoberta aos quatro anos e que foi assumido, ainda por longo tempo, como retardado ou autista. Seu depoimento sobre o comportamento do jovem, em fase inicial de aprendizagem em escola de surdos, ilustra com precisão a disjunção a que nos referimos: "Ele parecia vivo e animado, mas imensamente desconcertado: seus olhos eram atraídos pelas bocas que falavam e pelas mãos que gesticulavam dardejavam de nossas bocas para nossas mãos, inquisitivos, incompreensivos e, parecia-me, anelantes ${ }^{21}$ (Ibid.: 42).

Dispor ou não dispor de uma língua se relaciona também com as condições sociais. Em uma escola para surdos referida por Sacks, em Fremont, as crianças provêm de lares seguros. Junto com a língua de sinais, uma cultura surda se elabora (Ibid.: 56-57). Em outra escola, Braefield, apesar de uma correspondente inteligência, Sacks encontra um comportamento "sem espontaneidade, segurança, desenvoltura"22 (Ibid.: 56). Além da surdez, as condições sociais impuseram às crianças "lares onde os pais não sabem comunicar-se com eles [...] onde elas não podem absorver informações básicas sobre o mundo"23 (Ibid.: 56).

Sacks mostra ainda outra situação, referindo um estudo de Susan Scheller, sobre a aquisição da LS como primeira língua por um homem de 27 anos, com surdez pré-linguística. Apesar da situação extraordinária de enfrentar tal aprendizagem em idade adulta ${ }^{24}$, Ildefonso desenvolve sua competência linguística e interacional. Sacks apresenta duas hipóteses. Uma delas é a de "uma conservação incomum da flexibilidade neuronial" 25 (Ibid.: 167). Mas ele mesmo considera a segunda hipótese como mais interessante: "os sistemas gestuais (ou 'sinais nativos') inventados por Ildefonso e seu irmão [igualmente surdo] [...] poderiam ter funcionado como uma 'protolíngua"'26. Sua competência linguística teria sido aí desencadeada, dentro do período crítico - podendo então ser acionada e desenvolvida "quando exposta a uma verdadeira língua de sinais, muitos anos depois"27 (Ibid.: 167).

A segunda hipótese de Sacks pode ser complementada. Na própria elaboração dos sinais inventados pelos dois irmãos, em sua necessidade de interação, o que ocorre é o exercício de uma verdadeira comunicação. Na ausência de um sistema de regras mais avançado e de intercessores que ofertassem uma cultura transmitida, os irmãos desenvolvem uma protolíngua - esta, por mais simples e limitados que fossem os elementos de código, correspondia a uma invenção. A simplicidade da estrutura é compensada (em termos neurológicos) pelo fato de ser uma construção, uma criação entre as duas mentes. Trata-se de uma comunicação
${ }^{21}$ No original: "He looked alive and animated, but profoundly baffled: his eyes were attracted to speaking mouths and signing hands - they darted to our mouths and hands, inquisitively, uncomprehendingly, and, it seemed to me, yearningly".

${ }^{22}$ No original: "lacking spontaneity, confidence, social ease".

${ }^{23}$ No original: "homes where parents cannot communicate with them [...] where they cannot pick up basic information about the world".

${ }^{24}$ Os neurologistas assinalam que há uma idade crítica para aquisição de uma língua até a chegada da puberdade. Já mesmo a partir dos 5 anos, ocorrem dificuldades de fluência e de competência gramatical se até aí não houve aquisição de língua.

${ }^{25}$ No original: "an unusual retention of neuronal plasticity".

${ }^{26}$ No original: "the gestural systems (or 'home signs') set up by Ildefonso and his brother [equally deaf] [...] could have functioned as a "protolanguage"'.

${ }^{27}$ No original: "with exposure to genuine sign language many years later". 


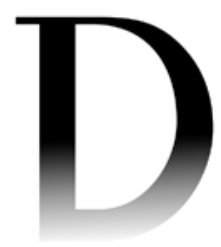

${ }^{28}$ No original: "Why is the uneducated deaf person isolated in nature and unable to communicate with other men? Why is he reduced to this state of imbecility?".

${ }^{29}$ No original: “The deaf generate sign language wherever there are communities of deaf people; it is for them the easiest and most natural mode of communication".

${ }^{30}$ No original: "Prior to 1817 , a deaf American traveling across the States would encounter sign dialects incomprehensibly different to his own".

não direcionada por uma língua existente e complexa - mas de uma primeira língua, nativa, gerada pelo processo comunicacional.

\section{Geração da língua}

Sacks faz algumas observações que sublinham a necessidade interacional como dinâmica básica para o desenvolvimento de uma língua. O abade Sicard se perguntava, no final do século XVIII: "por que a pessoa surda sem instrução é isolada na natureza e incapaz de comunicar-se com os outros homens? Por que ele está reduzido a esse estado de imbecilidade?”28 (Ibid.: 24). Sua própria resposta era que a ausência de símbolos para articular as ideias leva a uma inexistência total de comunicação.

Devemos inverter a perspectiva: é a ausência de comunicação que inviabiliza tanto a aquisição dos símbolos socialmente disponíveis como a invenção de códigos requeridos para encaminhar situações de realidade.

A barreira para o desenvolvimento da inteligência evidencia a comunicação como necessidade fundamental da espécie. O ser humano pode talvez dispor de competências inatas para a linguagem; mas é evidente que, na ausência de comunicação, esse possível inatismo é inoperante. Em todo caso, parece igualmente natural o que percebemos com a necessidade comunicacional: a busca da interação entre os indivíduos e, portanto, dos processos para interagir.

Por meio do livro de Sacks, aparecem evidências de um surgimento local, espontâneo, de sistemas de sinais entre surdos, seja na forma de línguas de sinais, seja de jargões ou sinais nativos, em diferentes graus de complexidade. "Os surdos criam línguas de sinais onde quer que haja comunidades de surdos; para eles, esse é o modo de comunicação mais fácil e natural"29 (Ibid.: 31). Foi a observação da língua de sinais nativa dos surdos pobres de Paris que levou o abade de L’Épée à fundação de uma escola para surdos em 1755.

"Antes de 1817, um americano surdo que viajasse pelos Estados Unidos encontraria dialetos de sinais incompreensivelmente diversos do seu"30 (Ibid.: 144). Contrariamente a uma crença difundida em uma língua de sinais universal, o que caracteriza o surgimento local das línguas de sinais é sua vinculação às circunstâncias da experiência vivida. Mesmo a unificação por país se dá apenas por meio de esforços sistematizadores coordenados.

Inferimos que a lacuna coloca como necessidade fundamental o desenvolvimento de sistemas interacionais para o exercício da comunicação. Aquela proliferação no surgimento de línguas e dialetos é desenvolvida de modo tentativo, por experiências interacionais coerentes com o que se busca comunicar. Mas entre suas condições de possibilidade é fundamental o encontro de uma alteridade 
em que um mínimo de compartilhamento esteja presente, em que o encontro de percepções seja viável.

O jovem surdo Massieu, que foi educado pelo abade Sicard, embora inicialmente ignorante da língua de sinais, teve sua formação dinamizada pelos sinais nativos que desenvolvera, em criança, na convivência com seus cinco irmãos surdos (Ibid.: 47).

Sacks refere depoimento sobre uma escola para surdos que adotava enfaticamente a oralidade surda, recusando aos estudantes a língua de sinais. $\mathrm{Na}$ ausência dos adultos, "os sinais floresciam na escola, irreprimíveis apesar dos castigos e proibições" 31 (Ibid.: 23). Os jargões de sinais se mostram aí como surgimento local de códigos.

Nessas circunstâncias, o que observamos - para além da questão de uma aquisição deslocada da situação normal - são processos comunicacionais que, malgrado a disjunção inicial, levam à geração de línguas de sinais. Sacks observa que "os sinais nativos que Massieu criou, e que aquelas crianças isoladas em idade pré-escolar criaram, são sistemas gestuais simples que podem apresentar uma sintaxe rudimentar e morfologia de um tipo muito limitado"32 (Ibid.: 152).

Não só as crianças: "também [adultos] acabam por inventar sistemas de gestos [...] pelos quais podem comunicar necessidades e sentimentos básicos a quem os cerca" $^{33}$ (Ibid.: 152). Por outro lado, esses mesmo geradores de línguas não conseguem "dar o salto qualitativo, passando de um sistema gestual desse tipo para um sistema linguístico completo, inteiramente regido pela gramática"34 (Ibid.: 152).

O linguista Derek Bickerton considera que criações complexas precisam de pelo menos duas gerações. Sacks observa que gerações sucessivas fazem evoluir crescentemente uma língua de sinais. Refere como exemplo a língua desenvolvida na ilha Martha’s Vineyard. Até o início do século XX, os surdos chegaram a compor $25 \%$ da população, distribuídos entre quase todas as famílias. A população se tornou bilíngue e a surdez deixava de ser considerada patológica, sendo assumida simplesmente como um modo de estar em interação.

Essa observação faz ver o processo de criação de uma língua como fenômeno histórico, que pede patamares de elaboração sucessiva. A partir de necessidades básicas, elaboração de "sinais nativos", uma vez que estes estejam estabelecidos, os códigos postos passam por experiências sucessivas, adaptação a necessidades diversificadas, interações mais sutis, para atender a objetivos mais complexos. Chegam, assim, às línguas de sinais. O sistema de regras se desenvolve a partir dos compartilhamentos anteriores: nos sentimentos básicos, apenas a percepção da necessidade é compartilhada; no segundo momento, compartilha-se já o jargão elementar. O exercício tensionado das próprias regras é o que as desenvolve, nas circunstâncias específicas de seu acionamento.
${ }^{31}$ No original: "signing flourished at the school, was irrepressible despite punishment and prohibition".

${ }^{32}$ No original: "the 'home signs' that Massieu developed, and that these isolated preschool children developed, are simple gestural systems that may have a rudimentary syntax and morphology of a very limited sort".

${ }^{33}$ No original: "[adults] too will invent gestural systems [...] by which they can communicate basic needs and feelings to their neighbors".

${ }^{34}$ No original: "make the qualitative leap from such a gestural system into a complete, fully grammaticized linguistic system". 


\section{INFERÊNCIAS E DERIVAÇÕES: RESULTANTES DO DIÁLOGO}

A comunicação não aparece no livro de Sacks como questão, como objeto de esquadrinhamento reflexivo. Não é um problema a ser resolvido - mas uma noção produtiva para apreender e esclarecer as questões surgidas no problema estudado. A comunicação se evidencia como aspecto central, articulador dos processos estudados pelo autor.

Sacks mostra assim, pelo simples uso da palavra, toda uma variedade de características, de processos em que a comunicação comparece. Com base nessas características e em nossas inferências pontuais, podemos fazer agora derivações sobre três aspectos em que a situação-limite viabiliza interpretações mais abrangentes.

\section{Comunicação e linguagem}

O primeiro aspecto diz respeito às relações fundamentais entre comunicação e linguagem. Embora o enfoque principal de Sacks se refira às línguas de sinais e à interação entre surdos, essa perspectiva é relacionada aos processos abrangentes da comunicação humana - por exemplo, quando trata da aprendizagem da língua oral segundo Vigotsky; ou dos processos gerais de surgimento da língua (Chomsky, Edelman) e mesmo de sistemas para além da língua (formulações matemáticas, jogo de xadrez). Isso faz perceber, correlatamente, conexões entre a geração e a aquisição de línguas de sinais e os processos gerais da comunicação humana. Podemos, portanto, ampliar o que aprendemos sobre a situação-limite, percebendo aí características gerais do fenômeno comunicacional.

A comunicação aparece como base do processo de aquisição de uma língua. As referências a Vygotsky assinalam a especificidade dessa aquisição, a partir de uma articulação comunicacional entre as percepções do bebê e os sistemas já culturalmente organizados, recebidos por meio do adulto intercessor.

A comunicação aparece ainda como processo de internalização da linguagem. Recebemos o acervo cultural de nosso ambiente social, primeiro pela aquisição de língua (já cultura), que de modo subsequente abre caminho para todos os demais processos e construções sociais que caracterizam nossa cultura. A voz do outro em mim, relacionando-se à percepção espontânea da alteridade e do mundo (Merleau-Ponty, 2002), alimenta nossa potencialidade comunicacional.

Sacks enfatiza igualmente a relevância do uso da língua como processo comunicacional que não corresponde apenas à expressão do pensamento, mas também à escuta da cultura. Certamente, a língua viabiliza e direciona a comunicação que a utiliza. Esse uso, no entanto, incide também sobre o código. 
Podemos afirmar, portanto, que as línguas se transformam pela comunicação social (Braga, 2010b) - em decorrência dos usos, da busca de como expressar ideias e referências ao mundo, e ainda das inferências de ajuste a situações específicas. Sacks observa que "as línguas de sinais estão evoluindo quase explosivamente em nossa época” (Ibid.: 164). O que ele estuda no curto prazo é o que os etimologistas investigam na longa duração histórica.

Finalmente - e esta é uma das relações principais corroboradas pela obra - encontramos a comunicação como processo de invenção e desenvolvimento de códigos. Assim como nas demais relações, a situação-limite se mostra elucidativa de situações habituais. O indivíduo que não dispõe de uma língua adquirida em situação normal para interagir não tem condições de desenvolvê-la isolado. Mas tão logo encontra um semelhante nessas mesmas condições, ambos exercem, em conjunto, uma comunicação viabilizada apenas pela percepção, pelas habilidades motoras e pela necessidade compartilhada. $\mathrm{O}$ antropólogo Yves Delaporte observa que "o momento de encontro com seres semelhantes é o destaque em todas as histórias de vida [de surdos]" 35 que recolheu (2000: 390, tradução nossa). Desse processo decorre um código para interagir. Dos sinais nativos até uma língua completa, em patamares sucessivos, a comunicação se exerce como geradora - o que permite inferir que as linguagens em geral se elaboram em padrão similar.

\section{Códigos \& inferências}

O segundo aspecto para derivação é a multiplicidade de "sistemas descritivos", que se relaciona, no livro, com uma revisão da hipótese de distribuição fixa entre os dois hemisférios do cérebro, em favor de "papéis dinâmicos na execução de tarefas cognitivas" ${ }^{36}$ (Ibid.: 91). A referência, aqui, para Sacks, é o trabalho de Elkhonon Goldberg e seus colegas. A proposta de Goldberg

amplia o domínio da "língua" para o de "sistemas descritivos" em geral. Esses sistemas descritivos, na formulação desse pesquisador, constituem superestruturas impostas a sistemas elementares de "detecção de características" [...], existindo em operação na cognição normal uma variedade desses sistemas (ou "códigos"). Um desses sistemas, evidentemente, é a linguagem natural, mas pode haver outros - como linguagens matemáticas formais, notação musical, jogos, etc. ${ }^{37}$. (Ibid.: 91)

Fazemos um reparo inicial - para considerar que esses sistemas não são apenas descritivos - do mesmo modo que uma língua não é simplesmente referencial com relação ao mundo, mas também expressa sentimentos, formula
${ }^{35}$ No original: "L'instant de la rencontre avec des êtres semblables à soi est le point d'orgue de toutes les histoires de vie".
${ }^{36}$ No original: "dynamic roles in dealing with cognitive tasks".

${ }^{37}$ No original: "enlarge the domain of 'language' to one of the 'descriptive systems' in general. Such descriptive systems, in his formulation, constitute superstructures imposed on elementary 'feature detection' [...] a variety of such systems (or 'codes') being operative in normal cognition. One such system is, of course, natural language; but there may be many others - such as formal mathematical languages, musical notation, games, etc.". 


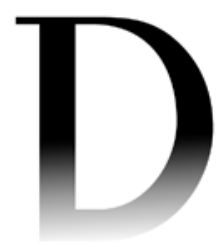

${ }^{38}$ No original: "It is characteristic of all of these [systems] that they are first approached in a tentative, groping way but later acquire an automatic perfection".

${ }^{39}$ No original: "It is characteristic of all of these [systems] that they are first approached in a tentative, groping way but later acquire an automatic perfection".

${ }^{40}$ No original: "[both hemispheres] are complementary, interacting; and between them they allow the mastery of new tasks".

o imaginado e, particularmente, é performativa. Os próprios sistemas referidos (linguagens matemáticas formais, notação musical, jogos), mais que descrever, permitem interações especiais sobre o mundo e entre as pessoas. Não é, portanto, excessivo caracterizá-los mais precisamente como sistemas interacionais. A proposta corrobora nossa perspectiva de dispositivos interacionais, constantemente desenvolvidos pelos participantes sociais e elaborados tentativamente, até se configurarem em modos estabilizados (Braga, 2011, 2015).

Sobre a percepção de que a espécie humana produz uma variedade de códigos, Goldberg dá atenção ao modo produtivo - que envolve duas estratégias: "É característico de todos esses sistemas o fato de a pessoa primeiro lidar com eles de um modo hesitante, inseguro, mas depois adquirir uma perfeição automática"38 (Ibid.: 91).

A distribuição dinâmica desses dois processos é que faria a diferença de atuação dos dois hemisférios: não como distinção entre tarefas especializadas (linguística ou por imagens; analíticas ou sintéticas; sequenciais ou simultâneas); mas sim - para todos os tipos de tarefas - dois estágios de elaboração:

O papel do hemisfério direito, assim concebido, é crítico para lidar com situações inusitadas, para as quais ainda não existe nenhum sistema descritivo ou código estabelecido - e também se julga que ele tem um papel na montagem desses códigos. Assim que esse código é montado, ou emerge, ocorre uma transferência de função do hemisfério direito para o esquerdo, pois este último controla todos os processos que são organizados segundo essas gramáticas ou códigos. ${ }^{39}$ (Ibid.: 91, grifo no original)

É importante a distinção entre os dois estágios: um, experimental, tentativo, que manuseia o inusitado e gera códigos; e outro nos quais processos já gramaticados se exercem pelo automatismo do código. Quando os códigos primeiro elaborados e depois automatizados - são acionados em circunstâncias não habituais, o processo tem que ser devolvido ao hemisfério direito, para tratamento das situações inusitadas. Como diz Sacks logo em seguida, "[os dois hemisférios] são complementares e interagem; e, pelo esforço conjunto, permitem novas tarefas" ${ }^{40}$ (Ibid.: 92).

Cabe aqui um segundo reparo. Não devemos imaginar que os processos dos dois hemisférios sejam diretamente criadores dos dispositivos interacionais (nem mesmo dos "sistemas descritivos" referidos por Goldberg). Essa elaboração não é apenas neuronal, mas desde o início comunicacional, dados os processos culturais e a internalização da alteridade. É preciso que a competência biológica seja alimentada pelo encontro humano com seus semelhantes e com a natureza 
cambiante - e na sequência histórica, com os aparatos técnicos desenvolvidos na e para a interação humana. Não devemos, portanto, confundir os processos do cérebro com a produção comunicacional - trata-se, no sistema neurológico, apenas das competências inatas de fazer inferências abdutivas e de codificar. O cérebro não é um computador, nem a comunicação ocorre isoladamente aí: ela exige o encontro entre espécimes, semelhantes em alguns aspectos básicos, entretanto diferenciados a ponto de não poderem se articular meramente por instinto. É apenas no momento do encontro que a comunicação tem condições de ocorrer, gerando o social em contexto de relações, que imediatamente se produzem, possibilitando o desenvolvimento de códigos interacionais.

É esse processo, aliás, que assegura a historicidade das relações sociais: estas não são produzidas diretamente pelo aparelho neuronal humano, estruturado no longuíssimo prazo. Os dispositivos interacionais (Braga, 2011) assim como os códigos e tendências inferenciais que os compõem têm a plasticidade e a agilidade das ocorrências singulares do mundo.

É fácil perceber a ocorrência frequente de tal processo nas situações específicas estudadas por Sacks; mas também em qualquer interação com acionamento de língua oral, escrita e outros sistemas interacionais. A própria lógica destes sistemas os leva ao enfrentamento de problemas, práticos ou teóricos, do mundo. O que implica a probabilidade de acabar encontrando situações inusitadas - isto é, ainda não contidas no alcance até então previsto para o código - resultando em constantes ajustes e reinvenções.

\section{A gênese da linguagem}

O terceiro aspecto refere-se ao processo gerador das línguas e linguagens - de sinais, oral, escrita, ou demais "sistemas descritivos" (na expressão de Goldberg).

Sacks refere duas hipóteses: ou a interação social apenas desencadeia a língua, que seria inata na forma de uma estrutura profunda "latente no sistema nervoso até ser despertada pelo efetivo uso da língua" ${ }^{41}$ (Ibid.: 72); ou a mente humana cria "as categorias e relações linguísticas de que precisa, como cria as categorias perceptivas sem prévio conhecimento, num mundo não rotulado" ${ }^{12}$ (Ibid.: 165).

A questão é fundante para a comunicação. A primeira alternativa, para a qual Oliver Sacks refere a teoria de Chomsky, oferece uma estrutura linguística profunda como base e origem da interação possível entre os seres humanos. A comunicação simplesmente seguiria essa estrutura inata, geneticamente dada desde sempre. O social - viabilizado pelas línguas e, no máximo, ativador destas, ancora diretamente no biológico. Reduz-se, portanto, àquilo que denominamos
${ }^{41}$ No original: "latent in the nervous system until kindled by actual language use".

${ }^{42}$ No original: "linguistic categories and relationships it needs, as [...] it creates perceptual categories, without prior knowledge, in an 'unlabelled' world". 


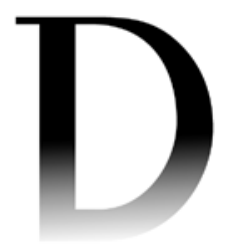

${ }^{43}$ No original: "whether any innate or rule-bound basis is needed for language development at all".

${ }^{44}$ No original: "being emotionally attracted to a Chomskian, or Cartesian, or Platonic idealism, to the notion of our language capacities, our powers of intellectual apprehension, all our perceptual powers, being innate

[...] but my observations of language acquisition, and of all developments in the individual or the species, tell me a much untidier story".

antes de comunicação fraca - que apenas atende a padrões determinados alhures. As transformações linguísticas se mostrariam como flutuações de uma gramática gerativa.

Sobre a segunda alternativa, Sacks refere Gerald Edelman perguntando "se alguma base inata ou regida por regras seria mesmo necessária para o desenvolvimento da língua"43 (Ibid.: 165) - perspectiva que dá então precedência à prática comunicacional como geradora. Nessa hipótese, a sociedade depende do biológico de um modo bem mais indireto - sendo gerada e desenvolvida pelo encontro de alteridades, no qual competências inatas se exercem criadoramente, em modos diferenciados.

O fato de que o desenvolvimento de uma língua dependa da interação humana (como mostrado no estudo de Sacks) é uma evidência de que não dispomos de estruturas linguísticas inatas. Ou, pelos menos, torna irrelevante a questão entre a hipótese do desencadeamento e a da criação em situação, pois nada se passa sem a prática social. Assim, a segunda hipótese, mais claramente adaptativa, se impõe como ângulo investigativo e como heurística principal para o estudo da comunicação.

Sacks oscila, no livro, entre essas duas tendências, para afinal confessar:

Me sinto emocionalmente atraído na direção de um idealismo chomskiano, ou cartesiano, ou platônico, da ideia de que nossas capacidades linguísticas, nossos poderes de apreensão intelectual, todas as nossas capacidades perceptivas, são inatos [...] mas minhas observações sobre a aquisição da língua, e todos os desenvolvimentos do indivíduo ou da espécie, contam-me uma história muito menos arrumadinha. ${ }^{44}$ (Ibid.: 177)

A própria reflexão de Sacks, embora referida à situação-limite, é diretamente generalizadora. A linguagem apenas surge em situações concretas e conforme os padrões da situação - seja para aquisição de língua existente, seja para produção de língua ou de inovações/derivações de língua disponível - conforme as necessidades, as características do contexto e os objetivos dos participantes.

\section{CONCLUSÃO}

Vimos como as limitações decorrentes da ausência de língua são impeditivas de processos culturais mais desenvolvidos. Tudo mostra que competências comunicacionais se desenvolvem originalmente pela articulação entre diferentes indivíduos, no grupo familiar, comunitário, ou tribal. Quando isso é postergado, o "momento do encontro" referido por Yves Delaporte se demarca como 
surgimento para a vida na cultura. São os exemplos em que surdos entram em contato - entre irmãos, na escola, na aldeia, por acaso. Não é obrigatório que o interlocutor tenha e ofereça uma língua já estabelecida - o encontro com o semelhante em competências e limitações dá as condições suficientes para a geração de língua. O exercício de suas competências motoras se mostra na forma do gesto que busca a interação, viabilizando uma comunicação mesmo na ausência de códigos anteriormente elaborados.

Se mesmo no encontro postergado - e, portanto, em condições particularmente desfavoráveis - o ser humano se mostra gerador de códigos ao entrar em interação, com maioria de razão o será nas condições favoráveis de interações articuladas com as primeiras experiências do mundo e da percepção.

A busca por comunicação parece ser natural, relacionada a várias competências independentes: percepção do mundo, capacidades motoras e uma competência mimética ${ }^{45}$ entrelaçada a competências inferenciais.

A disjunção circunstancial da situação-limite (esperançosamente corrigida por um encontro posterior) se mostra como o correlato negativo da situação mais habitual - de elaboração conjunta entre nossa competência mimético-inferencial e a interação com os outros. As características da comunicação que se tornam tão explícitas na situação-limite são, portanto, as mesmas que (eventualmente de modo menos dramático) estão presentes no processo mais recorrente da sociação.

Só há uma maneira de relacionar determinados gestos e suas combinações com os sentidos atribuídos: por um processo tentativo, em que sensações, desejos, medos e percepções do mundo, ultrapassando seu estado idiossincrático, busquem equilibrações pelo cotejo. O ensaio e erro permite o ajuste de sons e gestos, para expressar aproximadamente o mesmo entre os participantes. $\mathrm{O}$ idiossincrático se torna alteridade por uma aproximada tentativa de ordem comunicacional.

A diferencialidade humana é uma vantagem adaptativa: onde um espécime falha em sua tentativa, outro pode ser bem-sucedido. A diversidade favorece também a plasticidade dos processos - conforme o momento e os tipos de situação a ser enfrentada. Podemos então assumir como uma especificidade do ser humano sua potencialidade comunicacional articulada às diferenças entre os espécimes.

Essa vantagem adaptativa implica, entretanto, a necessidade de processo substitutivo, na ausência da articulação pelo instinto, que estabeleceria um comportamento pré-definido para todos os espécimes (ou tipos determinados de espécimes). Os processos geneticamente pré-estabelecidos pelo instinto ficam descartados pela mesma evolução que produz a variedade. Para que isso não 
se torne, inversamente, uma forte desvantagem para a sobrevivência da espécie, decorrente da dificuldade de ações concertadas, os modos de articulação devem ser negociados entre os espécimes diferenciados - levando à definição necessariamente plástica de modos articuladores, em função das preferências adaptativas definidas pelas circunstâncias.

Segue-se que o fenômeno comunicacional substitui o instinto padronizador e complementa a diferencialidade individual, permitindo a geração, de ordem cultural e não biológica, de códigos articuladores - com flexibilidade maior que a dos códigos genéticos. O específico da espécie não é propriamente acionar códigos - mas sim gerar códigos, substituíveis conforme as pressões do ambiente, social e natural.

Afirmamos, no início deste artigo, que a comunicação ocorre em uma realidade social histórica. Podemos agora ampliar essa proposição pela evidência de que o próprio fenômeno comunicacional, como o entendemos aqui, aparece como um dinamizador da historicidade do processo social. Diante de situações inusitadas, seres humanos em interação podem gerar códigos para rearticulação de seu comportamento. Estes, uma vez incorporados, passam a ser acionados de modo espontâneo em situações pertinentes - até que surjam novas situações, exigindo um refazimento ou uma complexificação. $\mathrm{O}$ trabalho inferencial, entretanto, é constante - não só para a geração e aquisição de códigos, mas continuadamente, para o ajuste à especificidade dos episódios interacionais.

Como a observação da situação-limite nos informa, um pré-requisito para a produção de códigos é a viabilidade de relações na alteridade. O risco corrido pelas crianças surdas, com suas consequências devastadoras se não estiverem em contexto favorecedor de aprendizagem ou invenção de línguas de sinais, evidencia ao mesmo tempo a potencialidade gerativa da comunicação e a necessidade constante, no ambiente humano, de assegurar condições favoráveis para seu florescimento. $\mathbf{M}$

\section{REFERÊNCIAS}

BRAGA, J. L. Midiatização como processo interacional de referência. In: MÉDOLA, A. S.; ARAUJO, D. C.; BRUNO, F. (Orgs.). Imagem, visibilidade e cultura midiática. Porto Alegre: Sulina, 2007. p. 141-167.

. Nem rara nem ausente, tentativa. MATRIZes, São Paulo, v. 4, n. 1, p. 65-81, 2010a. DOI: http://dx.doi.org/10.11606/issn.1982-8160.v4ilp65-81

. Comunicação é aquilo que transforma linguagens. Alceu, Rio de Janeiro, v. 10, n. 20, p. 41-54, 2010 b. 
BRAGA, J. L. Dispositivos Interacionais. In: ENCONTRO ANUAL DA COMPÓS, 20., 2011, Porto Alegre. Anais eletrônicos... Porto Alegre: UFRGS, 2011. p. 1-15. Disponível em: <https://goo.gl/pkdk6M>. Acesso em: 4 ago. 2017. . O grau zero da comunicação. E-Compós, Brasília, v. 18, n. 2, p. 1-17, 2015. DELAPORTE, Y. Etre sourd dans un monde entendant: destin, rencontre, transmission et rupture. Ethnologie française, Paris, p. 389-400, 2000. Disponível em: <https://goo.gl/33o11N >. Acesso em: 15 jan. 2017.

HAMM, M. Lapprentissage de la lecture chez les enfants sourds: Quels outils pédagogiques au service de quel apprentissage de la lecture? Education \& Formation, Hainaut, p. 37-44, Sept. 2008. Disponível em: <https://goo.gl/ nspN91>. Acesso em: 15 dez. 2016.

MERLEAU-PONTY, M. A prosa do mundo. São Paulo: Cosac Naify, 2002.

SACKS, O. Seeing Voices: A Journey into the World of the Deaf. Nova Iorque: Vintage Books, 2000 [1989]. 222 p.

. Vendo vozes: uma viagem ao mundo dos surdos. São Paulo: Companhia das Letras, 2010.

TARDE, G. Les lois de l'imitation. 2. éd. Paris: Kimé, 1993. Disponível em: $<$ https://goo.gl/RsW4vk>. Acesso em: 15 abr. 2013.

Artigo recebido em 14 de junho de 2017 e aprovado em 5 de julho de 2017. 